\title{
Range of dynamic impact of geotechnical works on reinforced concrete structures
}

\author{
Anna Wojtowicz ${ }^{*}$, Jarosław Michałek and Andrzej Ubysz \\ Wrocław University of Science and Technology, Faculty of Civil Engineering, Wybrzeże \\ Wyspiańskiego 27, 50-370 Wrocław, Poland
}

\begin{abstract}
Impact of geotechnical works related to plunging piles in the ground and modification of the condition of the soil foundation for concrete in the early stage of its bonding, and influence on adhesion of reinforcing steel to concrete can determinate the target capacity of a reinforced concrete structure. Impact of vibrations testing on bond strength is only possible on real designs or models subjected to dynamic impact. The paper presents mechanisms of adherence reduction caused by relative displacement of reinforcing steel and concrete. Moreover, dynamic influences (frequencies and vibration velocities) measured on structures within and around construction sites, where geotechnical works were carried out were also compared. Data obtained after their statistical analysis might become the basis for modelling an experiment.
\end{abstract}

\section{Motivation and scope of the study}

Temporary and spatial overlap of works, resulting mainly from short times of investment completion, nowadays occurs nearly on every construction site. In the case of works generating factors that may have a detrimental effect on other works being carried out in the neighbourhood, it is necessary to closely coordinate actions so as to minimize the negative effects of their interaction. Among such works, in particular, actions generating vibrations should be distinguished. The manner, place and conditions of their transfer to the environment, including facilities being erected and already existing ones, have a significant impact on the effects of these occurrences, and are difficult to clearly determine. Examples of such works are geotechnical works, such as pile driving, dynamic substrate compaction, sinking sheet piles or blasting works. Therefore, there is a need to constantly monitor the degree of vibration interactions in terms of threshold values and possible calibration of technology or limitation of impact time.

Civil works, run while renewing old buildings or constructing new ones within a builtup area must be prepared accordingly and proportionally to their impact upon surrounding structures. The basis for the result analysis and the assessment of safe vibration levels is typically formed by the following codes of practice: DIN 4150:1999 [1], EN 19935:2007 [2], PN-B-02170:1985 [3]. As most geotechnical technologies make it possible to reduce the energy of a single impact or vibration frequency, dynamic impact of works can

\footnotetext{
* Corresponding author: anna.wojtowicz@pwr.edu.pl
} 
be to some extent controlled. Examples of proper calibration of geotechnical works are given in works $[4,5]$.

It can therefore be noted that the problem of the impact of vibrations upon existing buildings and structures in the neighbourhood has already been defined. Investors increasingly commission monitoring and vibration measurements in the context of neighbouring structures security [6-10]. However, their harmful impact (and guidelines) upon facilities being put up, and in particular vibrations transferred to concrete in boarding, already in the phase of its bonding while adhesion to reinforcing steel is being built up has not been investigated, as demonstrated in [11].

Influence of vibrations upon concrete in the forming and bonding phase and its adhesion to reinforcing steel determines the target bearing capacity of a reinforced concrete structure. The study of the effects of dynamic impacts on adhesion is possible only on actual constructions or models subjected to identical interactions. As shown in [12], in the research model, it is necessary to implement vibration parameters close to real ones occurring in the technological process. Therefore, it is necessary to know the dynamic influences (frequencies and velocities of vibrations) occurring in the vicinity of construction sites where geotechnical works are carried out. For this purpose, it is reasonable to use existing databases obtained from vibration monitoring. Dr Jarosł aw Rybak (Wroclaw University of Science and Technology) provided the authors with the results of vibration measurements performed in the vicinity of geotechnical works, being a source of dynamic interactions. Data obtained after statistical analysis will help prepare an experiment on the impact of vibrations on steel to concrete adherence at the time of its bonding. Similar research concerning control of concrete properties at early stages of setting was already provided by authors of article [13].

\section{Problem of relative movement of steel bars in hardening concrete}

Adherence of steel to concrete, i.e. mutual transmission of forces between reinforcing bars and concrete, is the essence of reinforced concrete structures. Knowledge of this issue allows precise determination of deformations in steel and concrete. Paper [11] deals with the problem of steel-to-concrete adherence in reinforced concrete elements by providing mechanism of adherence destruction, methods used to determine adherence stresses and outlining analytical and numerical methods.

Four stages of adherence stress distribution [14, 15] can be distinguished, depending on displacement of bars in relation to concrete (Fig. 1). During the first stage, when element remains uncracked, mututal strain on concrete and steel is the same, which is caused by intermolecular forces of adhesion. This is the so-called primary adhesion. Smooth bars reach here maximum adherence stress, and gradually become destroyed (stage IVa). In the case of ribbed bars, the end of this stage involved displacement in relation to concrete and appearance of the first crackings (cracks A and B). Stage II involves irreversible damage in the element. Bar displacement keeps getting bigger and bigger, successive crackings appear (C). The first crushing of concrete (D, E) - stage III - causes an increase in stress resulting from steel and bar contraction. Destruction of concrete at rib face is preceded by longitudinal crackings parallel to reinforcement $(F)$. Maximum value of adherence stress of ribbed bar is achieved. Destruction of an element with ribbed bars may occur in two ways: by splitting the concrete cover (stage IVb) or tearing the reinforcement bar out (stage IVc). In the first case, through actions which restrict strains, the destruction is preceded by longitudinal cracks parallel to the bar axis. In the second case, concrete becomes truncated close to the rib face. 


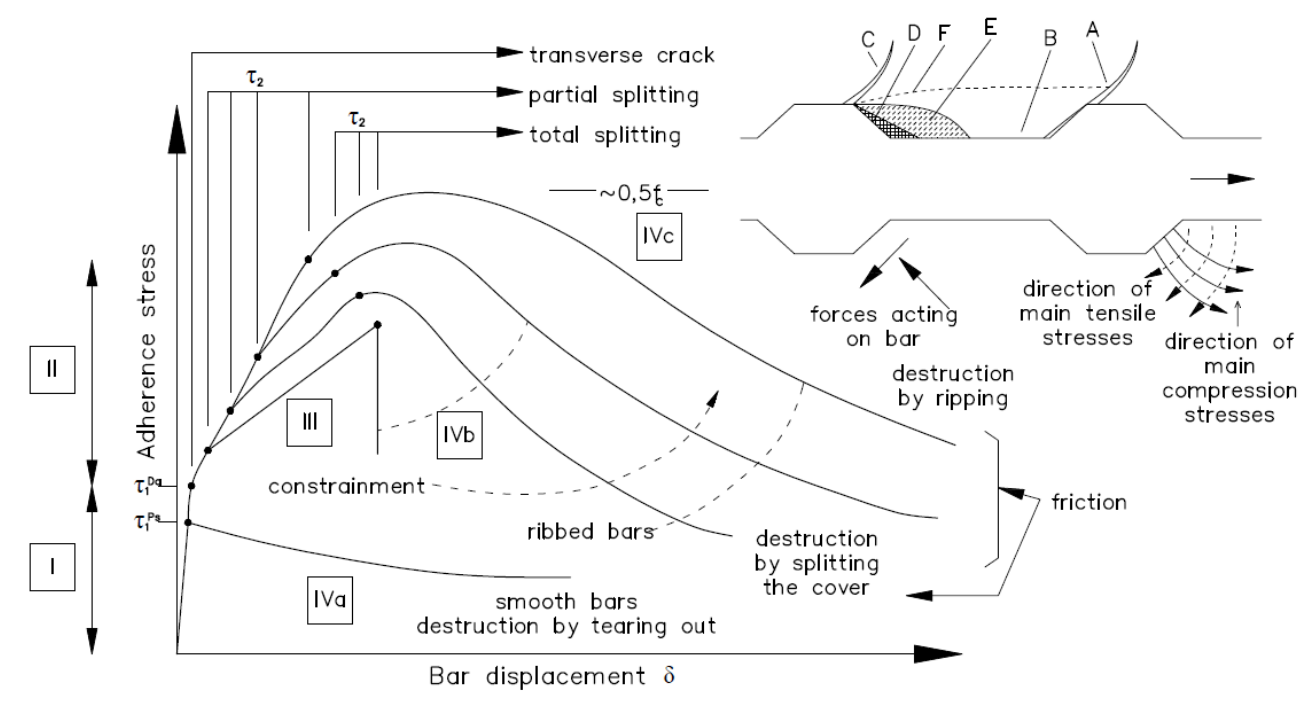

Fig. 1. Adherence stress pattern depending on bar displacement in relation to concrete [15] acc. to [14] and mechanism of adherence operation.

Impact of dynamic loads on green concrete may be observed in two phases, before and after the beginning of setting. During the phase of laying down and compacting concrete mix, one should expect an advantageous effects of vibrations improving compacting, spreading inside formwork and 'wrapping' reinforcement bars thoroughly [15-17]. Regrettably, also negative effect may appear, namely segregation of components - like for excessive vibrating [18]. Vibrations accompanying setting and hardening of concrete have negative impact only $[19,20]$.

\section{Construction site monitoring. General principles of measurement}

Analysed database includes the results of vibration measurements from the years 20102018, which originate from various geotechnical technologies.

The surveys were aimed at determining vibration levels (vibrations velocity), the source of vibrations being close to the protected object, successively for: maximum hammer drop height during pulse substrate compaction, sinking sheet piles with non-resonating vibratory hammer and plunging Franki piles with a pile driver. Current control was also exercised and in case of high or exceeded threshold values, technology correction was recommended.

For vibration measurement, the Minimate ${ }^{\circledR}$ Pro 4 sensor produced by Instantel ${ }^{\circledR}$ with a sampling frequency of $2048 \mathrm{~Hz}$ was used. During the measurement, the velocities higher than $0.1 \mathrm{~mm} / \mathrm{s}$ were observed at intervals of $15 \mathrm{~s}$.

The location of vibration sensors was dictated by the distance to the works carried out, allowing to assess the intensity of impacts transmitted to the objects while performing work causing vibrations. Sensors were most often located on reinforced concrete building elements.

Pictures 2-7 show the location of the sensor against the background of a chosen technology. 


\section{FORM-2019}

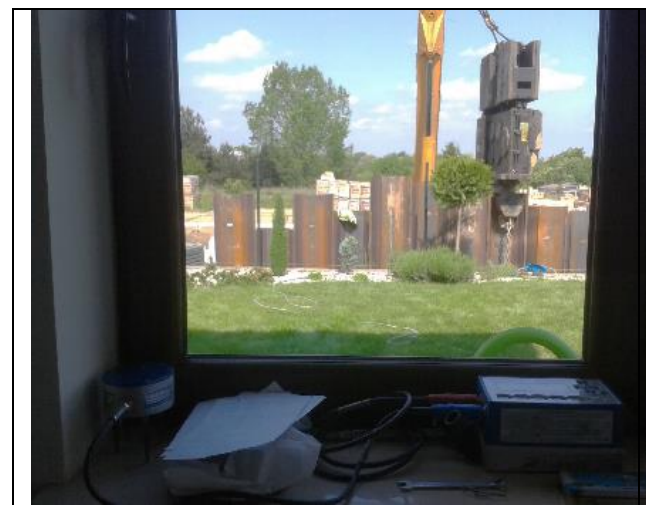

Fig. 2. Location of the sensor. Vibratory plunging and pulling out sheet piles, Komornki.

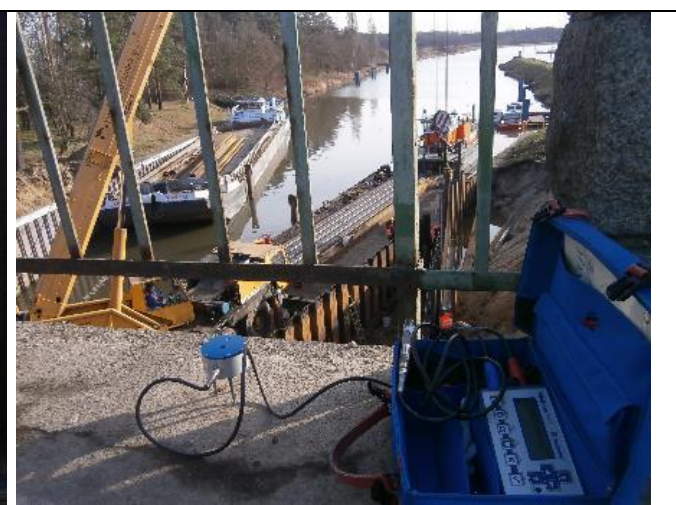

Fig. 3. Location of the sensor. Vibratory plunging and pulling out sheet piles, the bridge over the Rędzin Lock in Wrocław.

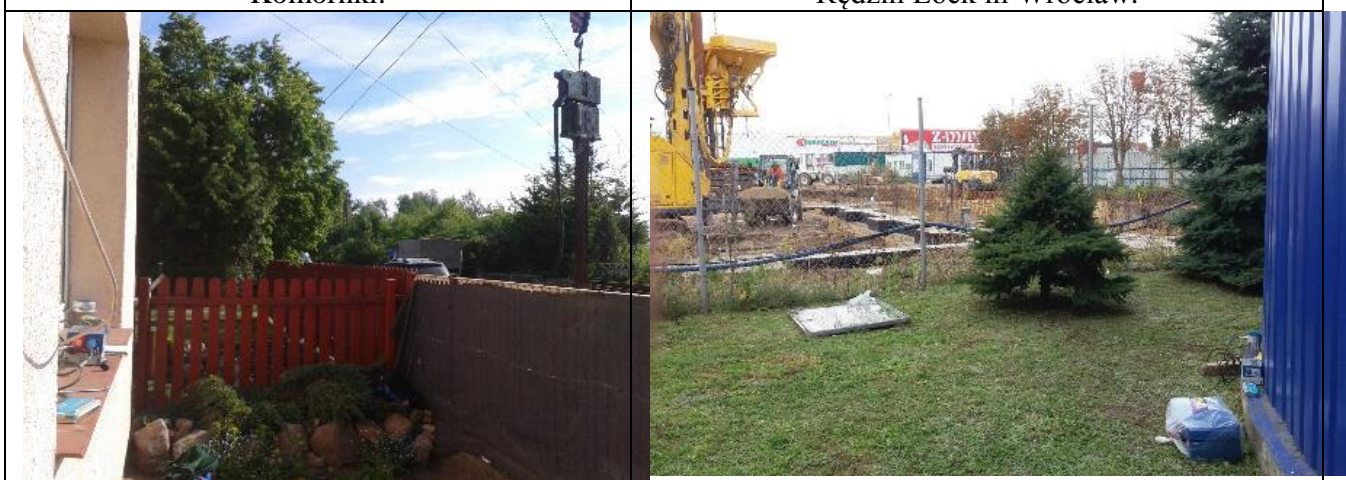

Fig. 4. Plunging of sheet piles, location of the sensor.

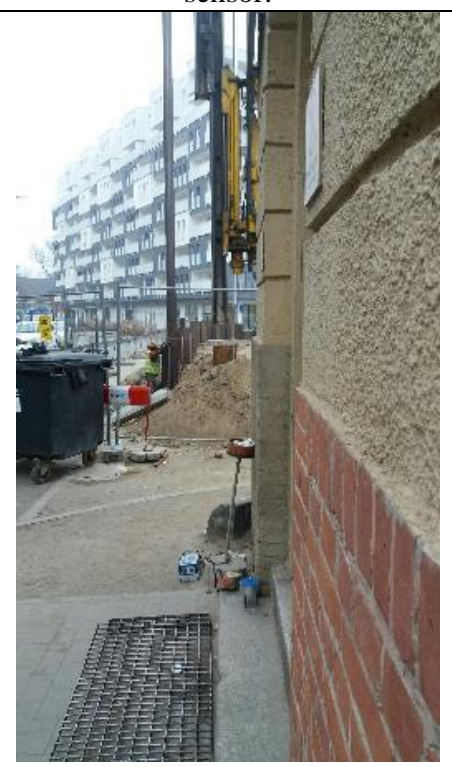

Fig. 6. Location of the sensor, plunging steel sheet piles, Dmowskiego St. in Wrocław.
Fig. 5. Location of the sensor, making gravel columns.

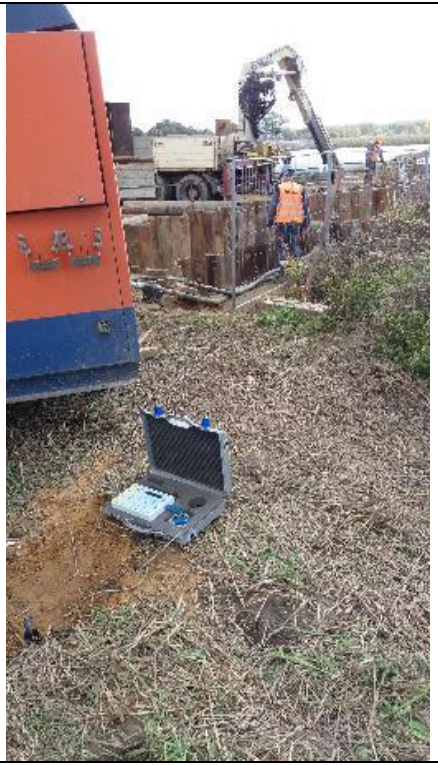

Fig. 7. Location of the sensor, driving steel pipes, Dobroszów Oleśnicki, 27 Czeska St. 


\section{Results of vibration measurements for selected geotechnical technologies}

The nature of vibrations generated by machines for geotechnical works can be twofold: harmonic excitation, e.g. work of a vibrator for plunging sheet piles or one-time extortion causing particles to deflect from the equilibrium state and return to it at their natural frequency. In the first case, the most important parameters of the description of the phenomenon are the frequency and velocity of vibrations. In the second case, to describe the vibrations, it is necessary to know the mass of the tested element in order to determine the natural frequency of the structure. In order to implement in the research model the values of upward extortion in real circumstances on a construction site and perform a universal assessment of the influence of dynamic impacts on a concrete element during its formation and bonding on the adhesion of steel to concrete, vibrations caused by the operation of vibrating machines should be analysed.

In the years 2010-2018, vibration monitoring was carried out for various geotechnical work technologies, among others vibratory plunging and pulling out of steel piles, pulse substrate compaction, making Franki piles, driving piles made of reinforced concrete, plunging steel pipes by vibration, making gravel columns.

The results for individual constructions are presented below. For each of them, the amplitude of vibration velocity for each direction was given (peak particle velocity $[\mathrm{mm} / \mathrm{s}$ ], frequency, as well as the vibration velocity vector (peak vector sum $[\mathrm{mm} / \mathrm{s}]$ ). Final recommendations based on the conducted vibration controls were also presented.

\subsection{Work of vibrator while driving sheet piles}

The vibration values obtained are summarized in Table 1. A histogram was constructed on the basis of the frequency of the occurrence of the vibration velocity vector (Figure 8) and frequency (Figure 9) in particular ranges.

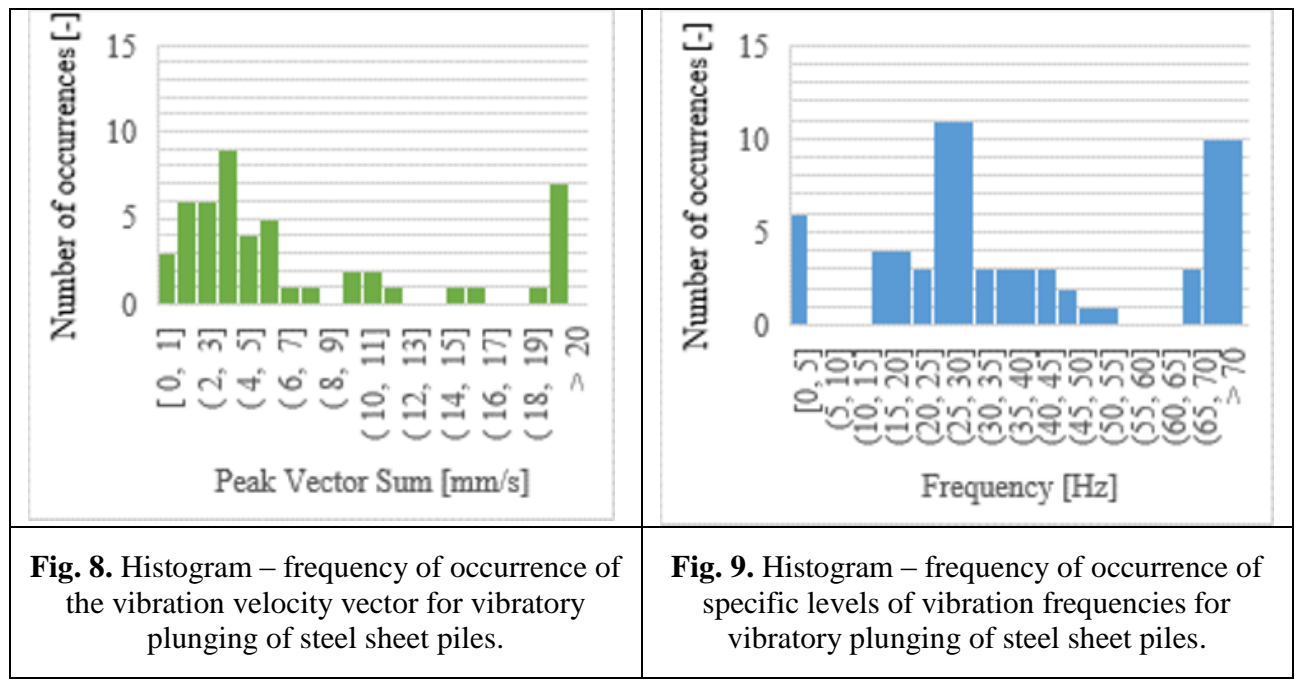

For the technology of vibratory plunging of steel sheet piles, the most frequent range of vibration velocity was the range $[0-6 \mathrm{~mm} / \mathrm{s}]$, while the frequency range was $[25-30 \mathrm{~Hz}]$. Larger values occurred for studies at a very close distance from the source of vibrations. 


\subsection{Pile driver's work for Franki piles}

Diagrams 10 and 11 show analogous vibration parameters for the work of a Franki pile driver. For this technology, we get peak particle velocity in the range of $0-3 \mathrm{~mm} / \mathrm{s}$. The most common frequencies are $25-30 \mathrm{~Hz}$ and frequency up to $5 \mathrm{~Hz}$.

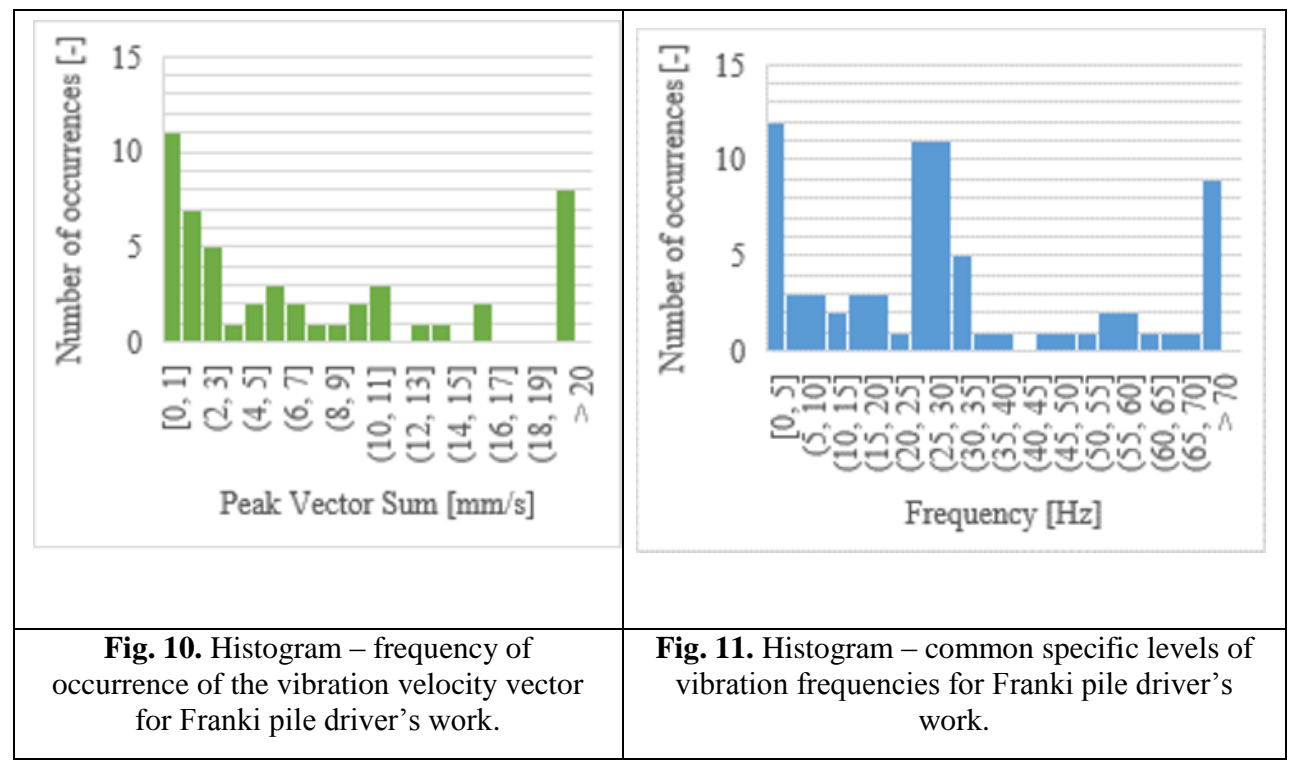

\subsection{Work of a pile driver for prefabricated piles}

In the case of the analysis of the vibration parameters obtained for the work of the prefabricated pile driver, the most frequently occurring value of peak vector sum lies in the range of $1-2 \mathrm{~mm} / \mathrm{s}$. However, the vibration frequency values are more diverse. The correct classification of vibration parameters depends on the number of measuring points. Driving of prefabricated piles has not been monitored as many times as, for example, vibratory plunging of sheet piles, which results in less accurate results.

\begin{tabular}{|c|c|}
\hline 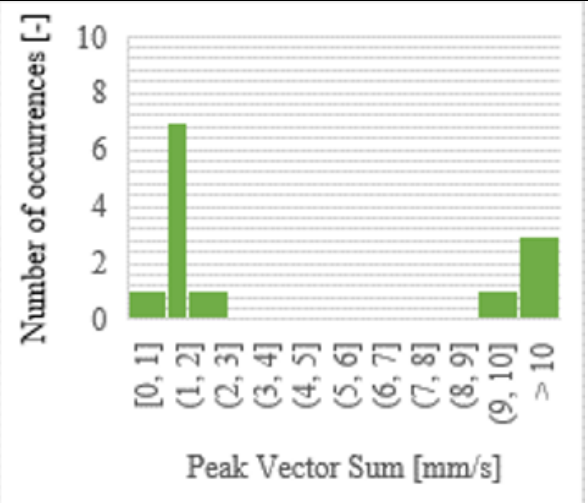 & 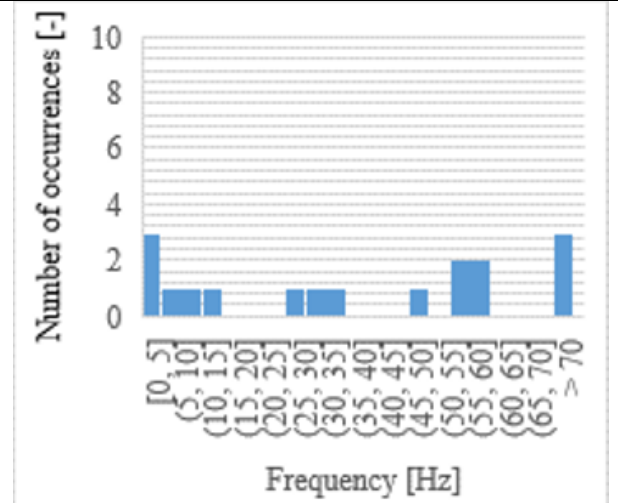 \\
\hline $\begin{array}{l}\text { Fig. 12. Histogram - frequency of occurrence } \\
\text { of vibration velocity vector for the work of a } \\
\text { precast pile driver. }\end{array}$ & $\begin{array}{l}\text { Fig. 13. Histogram -frequency of occurrence of } \\
\text { specific levels of vibration frequencies for the } \\
\text { work of a precast pile driver. }\end{array}$ \\
\hline
\end{tabular}




\subsection{Work of rapid pulse compaction}

The frequency of occurrence of vibration amplitude and frequency in specific intervals for pulse substrate compaction technology is presented in Fig. 14 and Fig. 15. For the discussed technology, the most common vibration velocities are $0-3 \mathrm{~mm} / \mathrm{s}$, and the frequencies are in the range of 5-25 Hz.

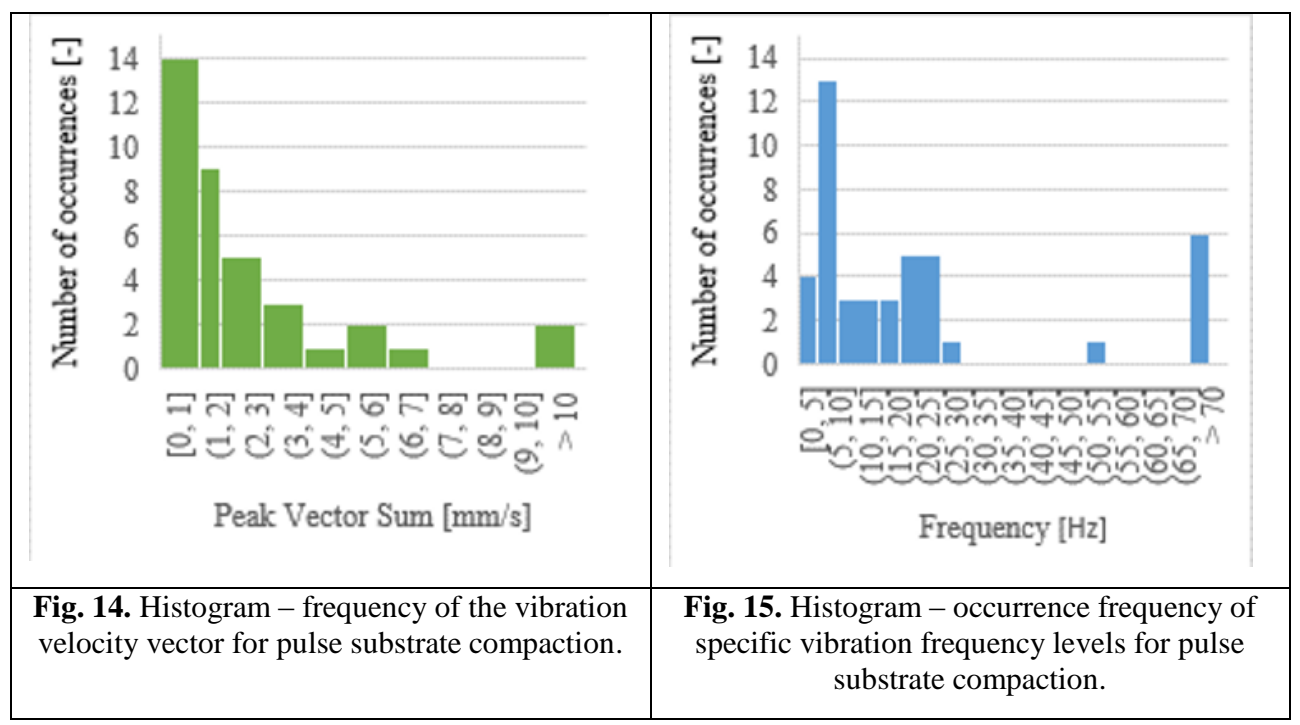

\section{Summary and conclusions}

Scientific studies investigating the possibility of damage to building structures due to dynamic interactions provide very divergent results of vibration parameters. The dynamic impacts presented above from construction sites allow for assessing the real intensity of these impacts. The frequencies of individual peak particle velocity and frequency values presented in diagrams 8-15 show that, depending on the source of vibrations, we note different values and sizes of their ranges. The monitoring carried out over the years 20102018 constituting the database, in $95 \%$, showed that the thresholds for vibration level in accordance with the guidelines [17-19] were not exceeded. In other cases, for fear of damage to existing facilities or furnishings, it was recommended to change the technology of works.

In order to implement in the research model the values of actual upward extortion on a construction site and a universal assessment of the influence of dynamic impacts on a concrete element during its formation and bonding upon the adhesion of steel to concrete, the data obtained for vibratory driving of sheet piles ought to be used. The nature of these vibrations may be measured less accurately in laboratory conditions. The optimum peak particle velocity range is $0-15 \mathrm{~mm} / \mathrm{s}$ and the optimum frequency is $25-30 \mathrm{~Hz}$.

The authors would like to address their gratitude to Dr Jaroslaw Rybak (Wroclaw University of Science and Technology) for his kind assistance and providing results of vibration monitoring. This paper has been written as part of the research project: "Industrialized construction process (Construction 4.0). Technological and methodological conditions of application of selected composite elements in civil engineering". The project is being carried out jointly with Peoples' Friendship University of Russia in Moscow. Research project PWr-RUDN 2017 no. 45WB / 0001/17 Industrialized Construction Process. 


\section{References}

1. DIN 4150:1999, Structural vibration - Effects of vibration on structures

2. EN 1993-5:2007 Eurocode 3: Design of steel structures - Part 5: Piling

3. PN-B-02170:2016-12 Ocena szkodliwości drgań przekazywanych przez podłoże na budynki. [in Polish]

4. J. Rybak, K. Schabowicz, Survey of vibrations generated in course of geotechnical works, $40^{\text {th }}$ Int. Conf. and NDT Exhibition on NDE for Safety, Pilsen, Czech Republic, Nov. 10-12 2010, NDE for safety: Defektoskopie 2010, 237-246 (2010)

5. A. Herbut, J. Rybak, Guidelines and recommendations for vibration control in the case of rapid impulse compaction, Advances and trends in engineering sciences and technologies II, CRC Press, Taylor \& Francis Group, 761-766, (2017)

6. J. Rybak, A.G. Tamrazyan, Calibration of rapid impulse compaction on the basis of vibration velocity control, $16^{\text {th }}$ Int. Multidisc. Sci. GeoConf. SGEM, 1, 715-722 (2016)

7. D. Papan, V. Valaskova, M. Drusa, Numerical and experimental case study of blasting works effect, IOP Conf. Ser.: Earth Environ. Sci., 44 (5), 052052 (2016)

8. F. Oliveira, I. Fernandes, Influence of geotechnical works on neighboring structures, 17th Int. Multidisciplinary Scientific GeoConference SGEM, 17 (12), 993-1002 (2017)

9. M. Wyjadłowski, Methodology of dynamic monitoring of structures in the vicinity of hydrotechnical works - selected case studies, Stud. Geotech. Mech., 39(4), 121-129 (2017)

10. W. Brzakała, M. Baca, The measurement and control of building vibrations in course of sheet pile wall and Franki pile driving, 17th Int. Multidisciplinary Scientific GeoConference, SGEM 2017, Albena, 17 (12), 929-936 (2017)

11. A. Wojtowicz, J. Michałek, A Ubysz, How vibrations affect steel-to-concrete adherence. MATEC Web Conf., 251, 02045 (2018)

12. M. Kijana, Metody wyznaczania wartości naprężenia przyczepności pomiędzy betonem a stalą zbrojeniową, Przegląd Budowlany, 6, 38-42 (2015)

13. R. Sieńko, M. Zych, Ł. Bednarski, T. Howiacki, Strain and crack analysis within concrete members using distributed fibre optic sensors, Structural Health Monitoring, Article in Press. (2018)

14. Model Code, Final Draft - Volume 1. FIB Biuletin 65 (2012)

15. S. Marx, Concrete production under traffic vibration. The $11^{\text {th }}$ Annual International fib Symposium ,C Concrete :21st Century Superhero-Building a sustainable future”. June 22-24, London, Session D-7 Structures \&Construction (CD), 1-8 (2009)

16. S. Harsh, D. Darwin, Traffic Inducted Vibrations and Bridge Deck Repairs. Concrete International, 8 (5), 36-42 (1986)

17. FIP Guide to good practice: Repair and strengthening of concrete structures. (Thomas Telford Services Ltd., London 1991)

18. A. Ansell, J. Silfwerbrand, The vibration resistance of young and early age concrete. Structural concrete, 4 (3), 125-134 (2003)

19. S. Freyne, M. Watkins, Acceptable vibrations on green concrete final report. State Study 252 (2013)

20. M.E. Arslan, E. Yozgat, S. Pul, M. Husem, Effects of vibration time on strength of ordinary and high performance concrete, $4^{\text {th }}$ WSEAS international conference on Energy and development - environment - biomedicine, 270-274 (2011) 